\title{
Health insurance for the poor: impact on catastrophic and out-of-pocket health expenditures in Mexico
}

\author{
Omar Galárraga $\cdot$ Sandra G. Sosa-Rubí • \\ Aarón Salinas-Rodríguez $\cdot$ Sergio Sesma-Vázquez
}

Received: 13 February 2009/Accepted: 18 August 2009/Published online: 16 September 2009

(C) The Author(s) 2009. This article is published with open access at Springerlink.com

\begin{abstract}
The goal of Seguro Popular (SP) in Mexico was to improve the financial protection of the uninsured population against excessive health expenditures. This paper estimates the impact of SP on catastrophic health expenditures (CHE), as well as out-of-pocket (OOP) health expenditures, from two different sources. First, we use the SP Impact Evaluation Survey (2005-2006), and compare the instrumental variables (IV) results with the experimental benchmark. Then, we use the same IV methods with the National Health and Nutrition Survey (ENSANUT 2006). We estimate naïve models, assuming exogeneity, and contrast them with IV models that take advantage of the specific SP implementation mechanisms for identification. The IV models estimated included two-stage least squares (2SLS), bivariate probit, and two-stage residual inclusion (2SRI) models. Instrumental variables estimates resulted in comparable estimates against the "gold standard." Instrumental variables estimates indicate a reduction of $54 \%$ in catastrophic expenditures at the national level.
\end{abstract}

O. Galárraga · S. G. Sosa-Rubí (ه)

Health Economics Unit, Center for Evaluation and Survey

Research, Mexican School of Public Health, National Institute of Public Health (INSP), Av. Universidad 655,

Cuernavaca 62508, Mexico

e-mail: srubi@insp.mx

O. Galárraga

Institute of Business and Economic Research (IBER),

University of California, Berkeley, CA, USA

\section{A. Salinas-Rodríguez}

Statistics Unit, Center for Evaluation and Survey Research, Mexican School of Public Health, National Institute of Public

Health (INSP), Av. Universidad 655, Cuernavaca 62508, Mexico

S. Sesma-Vázquez

Carso Institute for Health, Mexico City, Mexico
SP beneficiaries also had lower expenditures on outpatient and medicine expenditures. The selection-corrected protective effect is found not only in the limited experimental dataset, but also at the national level.

Keywords Mexico - Catastrophic health expenditures · Out-of-pocket spending $\cdot$ Health insurance .

Poor populations · Instrumental variables .

Econometric methods

JEL Classification $\mathrm{I} 11 \cdot \mathrm{I} 18 \cdot \mathrm{I} 38 \cdot \mathrm{O} 15 \cdot \mathrm{O} 38 \cdot$ 054

\section{Introduction}

This paper aims to estimate the treatment effect of health insurance targeted to the poorest families on catastrophic health expenditures (CHE) and out-of-pocket (OOP) health spending in Mexico. It draws on previous observational analyses of the issues surrounding health expenditure in Mexico [1-5], but adds a new dimension in the literature by using selection-correction methods for the potentially endogenous treatment variable. The goals of the paper are twofold. First, we compare instrumental variables (IV) results with the "gold standard" experimental evidence [6] in a limited dataset. Second, after that validation exercise, we use the IV method with a nationally representative database to explore if the protective effect found in the experiment can be extrapolated to the entire nation. The results suggest that Seguro Popular (SP) has a protective effect on CHE and OOP spending not only in the experimental (mostly rural) areas, but in the country as a whole.

The results presented here are relevant in the Mexican context, but may be of interest beyond the local context. 
The issue of the impact of universal health insurance on financial protection is of wide relevance across Latin America and other regions with low- and middle-income countries where the poor are disproportionately affected by excessive expenditure on health care.

The paper proceeds as follows. In "Background" we present a brief background of the SP program in Mexico. "Data and sample selection" presents the data and the sample selection methods, followed by "Methods" with the econometric methods used for the estimation of different models. "Results" shows the results of the paper, followed by a discussion in "Discussion". Finally, in the last section the paper offers some "Limitations and conclusions".

\section{Background}

Seguro Popular (SP, or "Popular Health Insurance") was implemented in Mexico as a comprehensive health reform effort to provide financial protection in health for the poorest segment of the population [7]. Until 2001, health insurance coverage in Mexico was directed only to employees working in the formal sector of the economy. Coverage for formal sector workers included the Mexican Social Insurance System (Instituto Mexicano del Seguro Social, or IMSS), the Government Workers' Social Security and Services Institute (Instituto de Seguridad y Servicios Sociales de los Trabajadores del Estado, or ISSSTE), as well as insurance programs for employees of such staterun enterprises as PEMEX (state oil company) and SEDENA (Ministry of National Defense).

Participants in the informal sector of the economy, as well as the self-employed, had to attend governmentsponsored facilities through the Ministry of Health (Secretaría de Salud, or SSA) or pay OOP for medical care at private health services. By 2002, there was evidence of excessive health-related spending for the poorest rural families in Mexico, particularly for the care of older adults (over 60 years of age) and for care during pregnancy [5, 8, 9]. Most catastrophic expenditures among the poor were attributed to outpatient care and medication. This situation is common among the poorest segments of the population in most developing countries where "a relatively small payment can mean financial catastrophe to a poor person or household, forcing them to reduce other basic expenses such as food, shelter, or their children's education" [10], or even suffer financial catastrophe [11].

Health insurance for protecting against financial catastrophe

From the earliest formal treatment on the subject, economic theory has emphasized that health insurance is demanded because it lessens financial risk against health payments for an unexpected illness $[12,13]$. The response is based on expected utility theory and the assumption that health insurance is desirable because of individual's riskaversion. Hence, Pauly [14] underlines the concept that a condition of purchasing an insurance is that the risk-aversion benefit must exceed both the payload and the moral hazard loss. However, benefits are also derived from the insurance's ability to make available medical care that would not otherwise be affordable. In other words, health insurance coverage would be the only way to gain access to costly health care [15].

The high degree of OOP spending, as well as evidence for the catastrophic health expenditure concentrated in poor and uninsured households in Mexico by 2001, motivated the implementation of a system of social protection in health [7]. The main objective was to financially cover access to health services and inputs for uninsured poor families. The mechanism used to reach this goal was a public, voluntary scheme that targeted primarily poor families without any other publicly funded health insurance.

A major problem in Latin America, and other regions with low- and middle-income countries, is the high percentage of households that must incur OOP expenditure. This form of financing frequently involves catastrophic health expenditure particularly among households living in poverty [16]. A multi-country analysis has shown that a group of countries in Latin America have high rates of catastrophic health expenditure [17], confirming the lack of financial protection, particularly among the poor in the region.

Different insurance mechanisms have been designed recently to protect the poor against excessive health expenditure, including community based health insurance [18, 19], national health insurance [19-23], and health insurance for the poorest groups of populations [7]. Mexico focused on the development of a voluntary insurance targeting the poorest population segments.

\section{Seguro Popular program}

The explicit goal of the SP program was to financially protect the poorest families (within the poorest two income deciles) that did not have any other socially provided health insurance coverage. Although enrollment campaigns were targeted at the poorest sections of the population in rural and in urban areas, the decision of whether to enrol into SP was a family's voluntary choice [7]. The program objectives were to assure:

1. protection of poor families against catastrophic health expenditures and its impoverishing effect; and

2. universal access to adequate secondary and tertiary medical care. 
Additionally, on the supply side, all SP-sponsored health facilities from public health providers had to offer a minimum level of health-services quality in order to belong to the SP-sponsored health facilities network.

The process of health unit accreditation to SP was rolled out gradually during 2001-2005. Five states (Aguascalientes, Campeche, Colima, Jalisco and Tabasco) were incorporated into the program in 2001 as part of a pilot study. An additional 15 states were integrated in the program in 2002; 4 more states were incorporated in 2003; and the remaining states were incorporated during 2004 and 2005. By the end of 2005, all 32 of Mexico's states had been incorporated, and approximately 4 million families (comprising about 12 million individuals) had signed up for the voluntary program [24].

Medical interventions are offered mainly through the public health network. The coverage of SP includes a health services package that covers 250 ailments and the drugs associated with them (as listed in the CAUSES or "Universal Catalogue of Health Services"). Nine types of group health services are covered: early detection and prevention; ambulatory medicine; dentistry; reproductive health; pregnancy, delivery and newborn care; rehabilitation; hospitalization; urgent care and surgery [25]. Affiliation to SP does not have restrictions based on current health status, pre-existing illness, or co-payments according to type of health care. SP care is financed primarily by federal and state governments; most contributions are made by the federal government, which pays to the different states a quota per SP-affiliated family. ${ }^{1}$ However, families also contribute to the annual payments based on their ability to pay: families classified into the first two income deciles are exempted from any annual payment, but those classified into higher deciles make an annual contribution that varies from about US\$50 to US\$770 [27]. A socioeconomic status questionnaire is applied to the head of the family at the beginning of the process of affiliation in order to differentiate families according to their income level.

During 2006 and 2007, federal contributions to the SP represented $75 \%$ of total resources, state contributions were around $24 \%$ and family contributions represented only $0.6 \%$ of total SP resources. Almost $90 \%$ of federal and state contributions are used to fund provision of health services listed in the Universal Catalogue of Health Services; $8 \%$ of the financial protection fund is used to cover high-cost diseases, and $3 \%$ are reserves to finance medical

\footnotetext{
1 The federal contribution per enrolled family consists of three components:(1) a quota per family provided by the federal government (the so called "social quota") that represents $15 \%$ of one minimum salary; (2) an additional federal contribution (named "aportación solidaria federal") that represents 1.5 times the quota per family; and (3) a state contribution that represents 0.5 times the quota per family [26].
}

infrastructure and unplanned medical care. Family contributions are part of the state reserve fund. ${ }^{2}$

Overall, through the first quarter of 2007, approximately 5.2 million (44\%) of the estimated 11.9 million eligible households nationwide had enrolled in the program [29]. Although indicators of coverage have widely demonstrated the proven capacity of the SP program to enroll a large group of uninsured households, there has been limited evidence for medium-term improvements in the financial protection of the poorest households.

Analyses of the trends and evolution of catastrophic and impoverishing health spending have shown a decreased incidence of catastrophic spending among the poorest households, but this trend was not clearly found in the case of OOP expenditures [8]. More recently, using experimental methods, King and colleagues found that SP was protective against $\mathrm{CHE}$. Their intent to treat (ITT) estimate reduced $\mathrm{CHE}$ by 1.9 percentage points (p.p.) from a (control group) baseline of $8.4 \%$, thus a reduction of $23 \%$. Their complier average causal effect (CACE) reduced $\mathrm{CHE}$ by 5.2 p.p. from a baseline of $9.5 \%$, thus a reduction of $55 \%$ [6].

A few recent studies have empirically estimated the effect of health insurance coverage on the incidence of catastrophic health spending in developing countries using econometric techniques and observational data [30-32]. This study uses an IV analysis, compares it to the experimental results, and estimates a causal effect of SP on catastrophic and OOP expenditures at the national level.

\section{Data and sample selection}

We analyzed the impact of SP on the incidence of CHE and OOP using two different data sources of household expenditure and insurance enrolment. We first used data from the Encuesta de Impacto del Seguro Popular (SP Impact Evaluation Survey) [33], and then we also used the Encuesta Nacional de Salud y Nutrición (ENSANUT 2005-2006) (National Health and Nutrition Survey) [34].

We selected a specific sample from each of the surveys as follows. For both surveys, we identified households where all members were enrolled into SP ("insured" group); that is, our "treatment" or "exposure" was that everyone in the household be officially enrolled into the SP

\footnotetext{
$\overline{2}$ By law, administrative costs cannot exceed $4 \%$ of the total federal budget transferred to the states for the SP program [28]. Analyzing the trends in operational costs of the National Commission for Social Protection in Health (or CNPSS for "Comisión Nacional de Protección Social en Salud") in the period 2004-2007, those costs have not exceeded $4 \%$ of the total costs of the SP [26]. However, the administrative costs of managing the funds specifically designed for catastrophic health spending were not considered.
} 
program. Then, we created a comparison group of households with no publicly funded insurance coverage ("uninsured" group); that is, our controls were households where no person had any type of health insurance. The idea was to remain with those families eligible for the SP program because, by law, families benefiting from other social insurance are not eligible for the SP program. (In sensitivity analyses, we relaxed the strict criteria for determination of treatment: we took a household as affiliated into the program if any member had signed up for the program).

The SP Impact Evaluation Survey is a panel dataset originally composed of 36,000 dwellings. There was baseline information (August 2005) for 32,506 dwellings, and first-wave data collected in mid-2006 with information for 29,836 dwellings [6, 35]. The data were collected in seven states in Mexico (Sonora, San Luis Potosi, Jalisco, Estado de Mexico, Guerrero, Morelos and Oaxaca). The main purpose of this survey was to measure (experimentally) the impact of SP among eligible households (poor households with no health insurance coverage). The criteria used to select the location of the treatment and control clusters were: (1) to include zones where the rate of penetration of the program was very low; (2) to include places where the incorporation of the SP program was being postponed. Note that this data was experimental in design; however, we used the follow-up data only, as if it were a cross-section so that we could maximize the comparability (external validity of the method) with the other data source. (Details on the experimental design have been presented elsewhere [35]). From the 29,836 households with relevant data (in the first-wave of data follow-up), we selected the following analytical samples: 4,033 SP-insured households and 16,759 uninsured households (see Table 1).

The ENSANUT 2006 is a cross-sectional dataset with nationally representative data, which was collected for 48,304 dwellings [34]. This dataset contains information about each individual's health, use of health services, socio-economic characteristics of households, access to health programs, and biological health indicators. From the original sample, we took 45,699 households with health expenditure data and health insurance data. The analytical samples included: 4,440 SP-insured households and 16,376 uninsured households. The characteristics for the sample are summarized in Table 1.

\section{Methods}

We undertook several types of analyses. First, we applied linear models $[36,37]$ with a basic econometric specification to analyze the impact of health insurance on OOP expenditures:
$Y_{j}=X_{j} \beta+T_{j} \delta+\varepsilon_{j}$

$T_{j}=Z_{j} \gamma+\mu_{j}$

where $Y$ is OOP spending, $X$ the covariate vector, $T$ the household enrolment into SP, $Z$ the IV $(Z \subset X)$.

In the naïve models, we assumed exogeneity (i.e., that the error terms $\varepsilon$ and $\mu$ were not correlated), and thus we could directly estimate Eq. 1 independently of Eq. 2. However, considering a potentially endogenous treatment variable, we also used a model with IV with the traditional two-stage least squares (2SLS) approach [38-40], where $\varepsilon$ and $\mu$ may be correlated. The likelihood of having OOP health expenditures may be related in a non-random fashion with the probability of having enrolled in SP. Households more prone to have high health care expenditures (relative to the level of household income), may have more incentive to sign up for SP.

Second, we defined expenditure as being catastrophic with a dummy variable equal to unity if household $j$ 's financial contributions to the health system exceeded $30 \%$ of spending after subsistence needs (US \$2 per capita) were met; and zero otherwise. This type of definition is the most widely used in the literature [41, 42], but there are other alternatives [17]. In sensitivity analyses, we changed the threshold of "catastrophe" to $20 \%$ and $40 \%$ of total nonsubsistence expenditures. To analyze CHE, we used a bivariate probit model $[38,40]$. The reason for doing this is that when we analyzed CHE, $T$ and $Y$ are both binary variables and their error terms might not be independent [43]. Under this specification, we have:

$$
\begin{aligned}
& \mathrm{CHE}_{j}^{*}=X_{j} \beta+T_{j} \delta+\varepsilon_{j} \\
& \mathrm{CHE}_{j}=1 \quad \text { if } \mathrm{CHE}_{j}^{*}>0 \\
& \mathrm{CHE}_{j}=0 \quad \text { otherwise } \\
& T_{j}^{*}=Z_{j} \gamma+\mu_{j} \\
& T_{j}=1 \quad \text { if } T_{j}^{*}>0 \\
& T_{j}=0 \quad \text { otherwise }
\end{aligned}
$$

Under the naive probit model assumption, the errors in Eqs. 3 and 4 are assumed to be uncorrelated. In the selection correction model, we assumed those errors have a bivariate normal distribution with a variance normalized to unity and a correlation coefficient denoted as $\rho$, as follows:

$$
\left(\begin{array}{c}
\varepsilon_{j} \\
\mu_{j}
\end{array}\right) \sim \operatorname{BVN}\left(\left[\begin{array}{l}
0 \\
0
\end{array}\right],\left[\begin{array}{ll}
1 & \rho \\
\rho & 1
\end{array}\right]\right)
$$

The correlation between the error terms captures the likelihood of having CHE and the propensity of enrolling into SP. A positive correlation coefficient would indicate that individuals who enroll in SP are more likely to have CHE. The system is identified if at least one variable in $Z_{\mathrm{j}}$ 
Table 1 Descriptive statistics, with and without Seguro Popular (SP), by data source

\begin{tabular}{|c|c|c|c|c|c|c|}
\hline & \multicolumn{3}{|c|}{ SP Impact Evaluation Survey } & \multicolumn{3}{|l|}{ ENSANUT } \\
\hline & $\begin{array}{l}\text { With SP } \\
(n=4,033)\end{array}$ & $\begin{array}{l}\text { Without SP } \\
(n=16,759)\end{array}$ & $\begin{array}{l}P \text { value } \\
(t \text { test })\end{array}$ & $\begin{array}{l}\text { With SP } \\
(n=4,440)\end{array}$ & $\begin{array}{l}\text { Without SP } \\
(n=16,376)\end{array}$ & $\begin{array}{l}P \text { value } \\
(t \text { test })\end{array}$ \\
\hline \multicolumn{7}{|l|}{ Outcomes } \\
\hline $\mathrm{CHE}^{\mathrm{a}}$ & $6.64(0.39)$ & $9.39(0.22)$ & 0.0000 & $4.71(0.32)$ & $6.67(0.20)$ & 0.0000 \\
\hline \multicolumn{7}{|l|}{$\mathrm{OOP}^{\mathrm{b}}$} \\
\hline Outpatient care & $269.9(18.8)$ & $456.9(15.6)$ & 0.0000 & $193.5(21.91)$ & $393.22(24.98)$ & 0.0001 \\
\hline Inpatient care & $303.3(40.4)$ & $594.1(26.3)$ & 0.000 & $270.82(62.13)$ & $595.42(54.11)$ & 0.0029 \\
\hline Medicines & $480.5(21.3)$ & $558.1(12.3)$ & 0.0033 & $333.21(18.02)$ & $528.38(18.96)$ & 0.0000 \\
\hline \multicolumn{7}{|l|}{ Covariates } \\
\hline \multicolumn{7}{|c|}{ Characteristics of the household head } \\
\hline Age & $46.7(0.25)$ & $47.6(0.13)$ & 0.0008 & $44.66(0.22)$ & $46.65(0.12)$ & 0.000 \\
\hline Female-headed & $21.7(0.65)$ & $22.8(0.33)$ & 0.1249 & $19.35(0.59)$ & $21.02(0.32)$ & 0.0147 \\
\hline Formal education (years) & $6.34(0.72)$ & $6.04(0.04)$ & 0.0003 & $5.04(0.05)$ & $5.71(0.03)$ & 0.000 \\
\hline Indigenous self-identity & & & & $23.28(0.63)$ & $24.55(0.33)$ & 0.0825 \\
\hline Speak indigenous language & & & & $10.29(0.45)$ & $12.87(0.26)$ & 0.000 \\
\hline \multicolumn{7}{|l|}{ Characteristics of the household } \\
\hline Asset index & $-0.25(0.01)$ & $-0.08(0.006)$ & 0.0000 & $-0.50(0.01)$ & $-0.29(0.01)$ & 0.000 \\
\hline Children $\leq 1$ & $11.85(0.51)$ & $15.16(0.27)$ & 0.0000 & $14.08(0.52)$ & $15.41(0.28)$ & 0.0282 \\
\hline Children $\leq 7$ & $49.61(0.79)$ & $47.04(0.39)$ & 0.0034 & $54.05(0.75)$ & $46.98(0.39)$ & 0.000 \\
\hline Adults $\geq 65$ & $19.24(0.62)$ & $20.95(0.32)$ & 0.0206 & $15.54(0.54)$ & $18.73(0.30)$ & 0.000 \\
\hline Someone with diabetes & & & & $3.83(0.29)$ & $3.52(0.14)$ & 0.322 \\
\hline Someone with hypertension & & & & $7.72(0.40)$ & $6.19(0.18)$ & 0.0002 \\
\hline Someone with gastritis & & & & $6.31(0.36)$ & $5.33(0.17)$ & 0.0117 \\
\hline Household size (\# of persons) & $4.30(0.32)$ & $4.42(0.02)$ & 0.0012 & $4.41(0.03)$ & $4.37(0.02)$ & 0.2863 \\
\hline Enrolled in oportunidades & $67.39(0.74)$ & $38.79(0.38)$ & 0.0000 & $19.91(0.60)$ & $11.16(0.24)$ & 0.000 \\
\hline \multicolumn{7}{|l|}{ Characteristics of the locality } \\
\hline Rural area & $97.21(0.26)$ & $92.6(0.20)$ & 0.0000 & $52.93(0.74)$ & $34.42(0.37)$ & 0.000 \\
\hline Deprivation index & $-0.03(0.01)$ & $-0.35(0.01)$ & 0.0000 & $-0.60(0.01)$ & $-0.76(0.01)$ & 0.000 \\
\hline \multicolumn{7}{|l|}{ Instrumental variables } \\
\hline Locality SP coverage & $28.74(0.39)$ & $10.24(0.13)$ & 0.0000 & $39.93(0.39)$ & $11.36(0.13)$ & 0.000 \\
\hline Randomized to treatment & $87.55(0.52)$ & $32.90(0.36)$ & 0.0000 & & & \\
\hline Incorporated by 2001 & $0.34(0.07)$ & $0.63(0.06)$ & 0.0304 & $28.16(0.68)$ & $8.67(0.22)$ & 0.000 \\
\hline Incorporated by 2002 & & & & $67.51(0.71)$ & $57.52(0.39)$ & 0.000 \\
\hline Incorporated by 2003 & & & & $79.36(0.61)$ & $77.40(0.33)$ & 0.0070 \\
\hline Incorporated by 2004 & & & & $95.10(0.33)$ & $91.11(0.22)$ & 0.000 \\
\hline
\end{tabular}

In households with SP, all members report to have enrolled into the voluntary health insurance program, whereas in households without SP, all members report not having any type of publicly funded health insurance. Standard error in parentheses

ENSANUT Encuesta Nacional de Salud y Nutrición (National Health and Nutrition Survey), CHE Catastrophic health expenditures, OOP Outof-pocket expenditures

Authors' calculations based on ENSANUT [34], SP Impact Evaluation Survey [33], Census data [52], and SP evaluation data [24]

${ }^{\text {a }} \mathrm{CHE}=1$ if a household's financial contributions to the health system exceed $30 \%$ of income remaining after subsistence needs (US $\$ 2$ per capita) have been met; and $\mathrm{CHE}=0$ otherwise

b Annualized OOP spending measured in Mexican pesos of 2006

is not in $X_{\mathrm{j}}$. Marginal effects of SP enrollment on the likelihood of CHE were estimated as the differences between the two mean CHE outcomes within each scenario: with and without SP.
Third, we also utilized the two-stage residual inclusion model to analyze CHE [44]. The two-stage residual inclusion (2SRI) method helps to address endogeneity in the specific case of a dichotomous endogenous variable 
with a dichotomous outcome variable. This method is the preferred option over the two-stage predictor substitution (2SPS), which mimics 2SLS for continuous variables. Under this econometric model, the first stage proceeded running a non-linear regression of the treatment on the covariate vector and the instruments. Then, the residuals from the first-stage regression were incorporated into a non-linear regression of the outcome on the covariate vector, the (endogenous) treatment, and the residuals.

To select an appropriate covariate vector we searched the literature $[17,45,46]$ and found the main determinants of CHE to be poverty, aging, chronic illnesses, low levels of insurance coverage, urban/rural differences, socio-economic status, types of illness, demographic composition of the household, and characteristics of the household head (age, sex, education). Health spending would be affected by the family's wealth/physical assets, and its income or financial assets as well as their insurance coverage. We used an asset index as a proxy for household wealth [47]. Additionally, the deprivation index at the municipality/ locality level helped to control for general levels of wellbeing at the local level [48]. Econometric methods to reduce selection bias have been used in several related studies [30, 31, 49, 50].

The main explanatory or "treatment" variable $(T)$ to be analyzed was enrolment into SP, a public insurance scheme for the poor and otherwise uncovered population in Mexico. Enrolment into SP would be determined by Eq. 2 above, which has a set of instrumental variables $(Z)$ that includes the same covariate vector $X$ as in Eq. 1 . The set of "instruments" would strongly affect the probability of a household being part of the SP program, but they would not be correlated with the outcome of interest (catastrophic expenditures in health) through channels other than the enrolment into SP.

The instrumental variables took advantage of the fact that SP was implemented gradually across the different 32 Mexican states. First, we used the year of incorporation as a proxy for the length of time that a particular state had SP. For example, if a state was incorporated by 2003 , a dummy variable for 2001 would be zero, a dummy for 2002 would also be zero, but the dummy variables for 2003 and 2004 would be equal to one. By 2005, all states were incorporated, so that 2005 serves as the reference year in the ENSANUT. Given that the states included in the sample were all incorporated by 2002, in the SP Impact Evaluation Survey the reference year was 2002. The marginal effect of the incorporation dummy measures the effect on the household SP enrolment probability of incorporation a year earlier. This instrument was implemented successfully in a similar context in Mexico [51].

Second, similar to the first set of instrumental variables, we used the level of penetration of the program at the locality level to help us determine the probability of enrolment. The logic was that households living in localities with higher SP penetration or coverage had higher probabilities of enrolling into the program. We constructed the variable with a ratio of SP enrolled households over eligible (uninsured households) at the locality level using the latest round of Census data [52]. Households located in areas where the level of diffusion of SP was higher tended to have higher probability of being enrolled into the SP program. We saw this instrumental variable as an aggregate continuous proxy for program participation at the household level. We assumed that the level of program diffusion or penetration had a direct impact on the behavioral choices of households; but with no underlying aggregate effect over expenditures, other than through the channel of insurance choice [53-55]. A similar identification method was used in an application to correct for insurance selfselection in Ecuador [56].

The geographic and temporal variations in incorporation and coverage rates helped us to identify SP household enrolment, independently of the outcomes of interest. Thus, the year-of-incorporation dummies, as well as SP coverage rates (as a continuous variable: $0-100 \%$ ), were excluded from Eqs. 1 and 3.

In addition to estimating the impact of SP on CHE, we also used the same (linear) econometric framework to estimate the effect of SP on OOP expenditures. We utilized the annualized OOP spending (in pesos of 2006). In sensitivity analyses we also used binary indicators of OOP spending, i.e., any positive expenditure related to outpatient care, inpatient care, and medicines, respectively.

For all model specifications, we compared the results from "naïve" estimates where the choice of health insurance use was assumed to be exogenous, to the results we obtained using models with instrumental variables. All analyses were conducted using STATA $^{\mathrm{TM}}$ [57], including procedures based on: reg, ivreg2, probit, biprobit, and $\mathrm{mfx}$ [58].

\section{Results}

Sample characteristics

Table 1 shows the outcomes and covariates for the two datasets. The main outcome was CHE. In the SP Impact Evaluation Survey, $6.64 \%$ of SP insured households and $9.39 \%$ of uninsured experienced CHE. In the ENSANUT, $4.71 \%$ of insured and $6.67 \%$ of uninsured households exhibited CHE (i.e., health expenditures over $30 \%$ of total household expenditures after accounting for subsistence needs, or US\$2 per day).

In terms of OOP expenditures, the SP Impact Evaluation Survey showed an average annualized outpatient care 
expenditure of $\$ 270$ (Mexican pesos of 2006) for SP affiliated households versus $\$ 457$ for non-insured; at the national level, the ENSANUT showed $\$ 193$ for the insured, and $\$ 393$ for the uninsured. For inpatient care, the insured population in the SP Impact Evaluation Survey spent $\$ 303$ pesos, and the uninsured spent $\$ 594$ pesos; while the national average in the ENSANUT was \$271 pesos for the insured and $\$ 595$ for the uninsured. Furthermore, the SP Impact Evaluation Survey population spent $\$ 481$ on medicines per year if insured and $\$ 558$ if they were uninsured; meanwhile the ENSANUT showed that the SP insured population spent $\$ 332$ in medicines, while the uninsured spent $\$ 528$ pesos per year. All the differences between insured and uninsured populations were significant in both surveys.

In terms of the covariates, the characteristics of the household-head included: age, female-headed, formal education, indigenous self-identity, speak indigenous language. For both uninsured and insured groups, the mean of the age of the household-head fluctuated between 45 and 48 years. The percentage of households that were femaleheaded was between 19 and 23\%. The number of years of formal education for the household head was between 5 and 6.3 years. ENSANUT data also showed that almost a quarter of the household heads consider themselves indigenous, and over $10 \%$ of them speak an indigenous language (other than Spanish).

Characteristics of the household included: the household asset index as a proxy of family income, household size, and benefits from other social programs (in particular the OPORTUNIDADES program). At this level, variables that denoted the composition of the family were: children who were 1 year old or younger, and children who were 7 years old or younger, as well as adults 65 years old or older. For the specific case of ENSANUT we included additional variables that informed us about the presence of some chronic health conditions among at least one of the members of the family (diabetes, hypertension and gastritis). SP-insured were more likely to have been diagnosed with diabetes. The mean for the household asset index was lower (or more negative) for both the SP-insured and uninsured populations, indicating lower levels of family wealth. The mean household size was about four members. Moreover, about one-half of the households have children 7 years of age and younger; and about one-fifth of households had adults 65 years or older.

Comparing insured and uninsured, we found differences in the percentage of families who reported to be beneficiaries of the OPORTUNIDADES program. Also, a considerably lower percentage of families from the ENSANUT survey reported to be benefiting from this program than in the other survey. Generally, for both data sources, SP-insured households were more likely to be benefited by OPORTUNIDADES. This result was consistent with the enrollment rules of SP that explicitly established OPORTUNIDADES families as a priority group.

At locality level, we incorporated variables that described the rural or urban condition of the municipalities and the deprivation index [48]. While the SP Impact Evaluation Survey (which was not nationally representative) showed $96 \%$ of the insured, and about $89 \%$ of uninsured, living in rural areas, there were $53 \%$ of SP insured households, and

Table 2 SP Impact Survey: naive and instrumental variables (IV) models for effect of SP on $\mathrm{CHE}^{\mathrm{a}}$ and $\mathrm{OOP}^{\mathrm{b}}$ health expenditures control for all covariates in Table 1. Robust standard errors in parentheses. OLS ordinary least squares, $2 S L S$ two-stage least squares, $2 S R I$ two-stage residual inclusion, $M E$ marginal effect

\begin{tabular}{|c|c|c|c|c|}
\hline & \multirow[t]{2}{*}{$\mathrm{CHE}$} & \multicolumn{3}{|l|}{ OOP spending } \\
\hline & & Outpatient & Hospitalization & Medicines \\
\hline \multicolumn{5}{|l|}{ Naive estimates ${ }^{\mathrm{c}}$} \\
\hline OLS & & $-195.2 * * *(34.4)$ & $-261.2 * * *(60.3)$ & $-71.0 * *(28.2)$ \\
\hline Probit (ME) & $-0.030 * *(0.004)$ & & & \\
\hline \multicolumn{5}{|l|}{ IV estimates ${ }^{\mathrm{d}}$} \\
\hline 2SLS & & $-447.1 * * *(71.8)$ & $-450.3 * * *(125.2)$ & $-110.9 *(58.9)$ \\
\hline Bivariate Probit (ME) & $-0.046 * *(0.007)$ & & & \\
\hline Correlation coefficient $(\rho)$ & $0.109 * *(0.042)$ & & & \\
\hline 2SRI (ME) & $-0.047 * *(0.007)$ & & & \\
\hline Residuals (ME) & $0.031 * *(0.008)$ & & & \\
\hline \multicolumn{5}{|c|}{$*$ Significant at $10 \%, * *$ significant at $5 \%, * * *$ significant at $1 \%$} \\
\hline \multicolumn{5}{|c|}{${ }^{a}$ CHE defined as OOP spending greater than $30 \%$ of survival consumption (over US $\$ 2$ per day) } \\
\hline \multicolumn{5}{|c|}{ b Annualized OOP spending measured in Mexican pesos of 2006} \\
\hline \multicolumn{5}{|c|}{${ }^{\mathrm{c}}$ Naive models assume exogeneity of the treatment variable } \\
\hline${ }^{\mathrm{d}}$ IV models deal with endoge & selection into SP & & & \\
\hline
\end{tabular}


$34 \%$ of the uninsured living in rural localities reported in the ENSANUT.

Instrumental variables applied in the experimental dataset

Table 2 presents the naïve and selectivity-corrected models using the SP Impact Evaluation Survey. The naïve effect of SP on OOP spending (which corresponds to Eq. 1 estimated independently) was a reduction of \$195 in outpatient care, \$261 in inpatient care, and \$71 in medicines (in pesos per year). In the naïve probit model (corresponding to Eq. 3 independently), there was a protective effect of SP on CHE of 3.0 p.p. The effect of SP on OOP expenditures was more protective in the IV estimation (Eqs. 1, 2 estimated together): outpatient expenses decreased by $\$ 447$; hospitalization by $\$ 450$; and medicines by $\$ 111$ pesos per year. The protective effect of SP on CHE increased to 4.6 p.p. in the bivariate probit model (Eqs. 3, 4 jointly); and to 4.7 p.p. in the 2 SRI model.

Instrumental variables in the nationally representative dataset

Table 3 reports the summary of naïve and instrumental variables models of the effect of SP on CHE and OOP spending for the National Health and Nutrition Survey (ENSANUT 2006). The naïve probit estimate of the effect of SP on CHE was protective: a household was 2.0 p.p. less likely to suffer CHE if enrolled in SP. Similarly, SP was protective of all OOP spending: per year, SP households spent $\$ 153$ pesos less than uninsured households in outpatient services, \$236 less in hospitalizations, and \$139 less in medicines when compared to the uninsured. Correcting for endogeneity, the impact of SP on $\mathrm{CHE}$ and OOP spending was generally more protective. The bivariate probit model estimates showed a protective effect of SP on CHE of 3.6 p.p.; the 2SRI model estimated a similar protective effect of 3.7 p.p. With regard to OOP expenditures, IV correction showed that SP insured households spent $\$ 171$ less on outpatient services, and $\$ 360$ less on medicines. Nevertheless, the effect of SP on hospitalization expenditures was not significant.

In both datasets (Tables 2, 3), the coefficients of correlation $(\rho)$ in the bivariate probit models were positive and significant. Likewise, the coefficients for the first-stage residuals were also positive and significant in the outcome equations under the 2SRI models. These results support the hypothesis of selectivity in the enrollment into SP.

\section{Sensitivity analyses}

When we utilized a more relaxed definition of SP enrollment (if any member of the household had signed up for the program), we also found protective effects on $\mathrm{CHE}$ and OOP spending; some of the results were of lesser magnitude, but still significant. Similarly, when we modified the threshold for the definition of "catastrophic" to $20 \%$ and $40 \%$ of total household expenditures after accounting for subsistence needs, we also found protective effects of SP; again, the results changed in magnitude, but they remained protective and statistically significant.

Other analyses included using the log transformation of OOP expenditures, OOP spending as a dichotomous variable (yes/no), as well as the supply side factors (availability of health clinics, doctors and nurses) at the municipality

Table 3 ENSANUT 2006: naive and IV models for effect of SP on $\mathrm{CHE}^{\mathrm{a}}$ and $\mathrm{OOP}^{\mathrm{b}}$ health expenditures control for all covariates in Table 1

\begin{tabular}{|c|c|c|c|c|}
\hline & \multirow[t]{2}{*}{$\mathrm{CHE}$} & \multicolumn{3}{|l|}{ OOP spending } \\
\hline & & Outpatient & Hospitalization & Medicines \\
\hline \multicolumn{5}{|l|}{ Naive estimates ${ }^{c}$} \\
\hline OLS & & $-152.6 * * *(29.1)$ & $-235.5 * * *(81.9)$ & $-139.0 * * *(22.7)$ \\
\hline Probit (ME) & $-0.020 * * *(0.004)$ & & & \\
\hline \multicolumn{5}{|l|}{ IV estimates ${ }^{\mathrm{d}}$} \\
\hline 2SLS & & $-171.0 * * *(64.1)$ & $-175.3(182.0)$ & $-360.0 * * *(54.9)$ \\
\hline Bivariate Probit (ME) & $-0.036 * * *(0.006)$ & & & \\
\hline Correlation coefficient $(\rho)$ & $0.146 * * *(0.045)$ & & & \\
\hline 2SRI (ME) & $-0.037 * * *(0.006)$ & & & \\
\hline Residuals (ME) & $0.031 * * *(0.009)$ & & & \\
\hline
\end{tabular}

* Significant at $10 \%, * *$ significant at $5 \%, * * *$ significant at $1 \%$

${ }^{\text {a }}$ CHE defined as OOP spending greater than $30 \%$ of survival consumption (over US $\$ 2$ per day)

b Annualized OOP spending measured in Mexican pesos of 2006

${ }^{c}$ Naive models assume exogeneity of the treatment variable

${ }^{d}$ IV models deal with endogeneity of selection into SP 
level. These analyses supported the overall conclusions of the paper. However, the supply side factor data reduced the sample size considerably, thus not allowing for full implementation of the models.

Finally, we ran regression models with and without taking advantage of the randomized assignment to treatment as an instrument $[59,60]$, and also as a covariate to control for non-compliance in the models using the SP Impact Evaluation Survey. The results presented in the tables are the best fitting models; however, making these changes did not qualitatively change the conclusions of the main results.

\section{Discussion}

The proposed IV models perform well when compared against the "gold standard" results obtained in the experimental setting. This paper's results on the effect of SP program participation on CHE are generally comparable to those found through a randomized controlled evaluation [35, 61]. King and colleagues found that SP reduces the probability of incurring CHE by $23 \%$ with ITT analysis and by 55\% using the CACE. Using IV methods in the (follow-up) experimental survey, we find a protective effect of $49 \%$.

Applying the IV method at the national level, using ENSANUT, we find a protective effect of $54 \%$ for the country as a whole. Hence, the selectivity-corrected, nationally representative results seem to suggest that SP has a protective effect for the entire country, not only in the pilot experimental areas.

On the other hand, there are some important differences between the experimental results [6]. The experiment did not find a protective effect of SP on medicine expenditures in the SP Evaluation Survey; however, using the alternative IV method we do find an important protective effect. Although the IV method using ENSANUT also found decreases in outpatient and medicine expenditures at the national level, it did not find significant effects in inpatient expenditures (and this result was the same using alternative definitions of SP enrollment at the household level, alternative sets of covariates and alternative sets of instrumental variables).

A major problem in Latin America, and other regions with low- and middle-income countries, is the high percentage of households that must incur in out-of-pocket health care expenditures. This form of financing frequently involves CHE, particularly among households within the first two deciles of income, or those living in poverty [16]. A multi-country analysis has shown that a group of countries in Latin America have some of the highest rates of CHE [17], confirming the lack of financial protection among the poor in the region. The results in our paper show the protective effect of health insurance for the poor.

\section{Limitations and conclusions}

The results in this paper show that the popular insurance system for the poor in Mexico has a protective effect on excessive health expenditures, and on most OOP healthrelated expenditures for the Mexican population.

The paper has some limitations. The definition of CHE does not consider all those households that postpone their health care for the lack of financial resources. That is, it does not address the issue of selection into CHE. Health expenditure is, by definition, conditional on utilization. Thus, there is another possible econometric specification to take into account the endogeneity generated by health seeking behavior. Such correction would require health status, clinical and outcomes data on nonusers to exogenously assess needed medical expenditures [62, 63].

Moreover, the present analysis does not include alternative indicators that can also describe the effect of the incidence of health expenditures on the household's financial status, such as impoverishing expenditures (spending that moves the household's economic status below the poverty line).

At the household level, the cross-sectional surveys do not provide information about the length of exposure to the program (i.e., how long the households have been enrolled in SP) or about the quality of the services offered, both of which could have an important effect on health expenditures.

In spite of the shortcomings, this paper presents a reasonable IV approach showing a robust protective effect of $\mathrm{SP}$ on CHE and on most OOP health expenditures. The impact of SP on the reduction of CHE was significant using the SP Impact Evaluation Survey; thus, replicating, and "validating" the IV method. We also found protective results with the ENSANUT using a nationally representative sample. The SP reduced expenditures in outpatient care as well as expenditures on medicines.

This paper provides the first selectivity-corrected evidence that the universal health insurance program for the poor in Mexico-Seguro Popular-has a protective effect on both catastrophic and out-of-pocket health expenditures not only at the limited localities included in the experimental evaluation, but at the national level. The lessons from Mexico may be of relevance to other low- and middle-income countries around the world trying to financially protect the poorest segments of society against excessive health spending. 
Acknowledgments We thank Martha María Téllez-Rojo, Gustavo Nigenda, and Miguel Angel González-Block for inviting us to participate in the Seguro Popular Program Evaluation, commissioned by the Mexican Ministry of Health (specifically by the Dirección General de Evaluación del Desempeño) to the National Institute of Public Health (INSP). The results presented in this paper constitute additional work conducted by the authors. The views do not represent the official position of any of the institutions that funded or facilitated that evaluation. The organizations did not have any role in study design, analysis, or interpretation; nor in the writing of the manuscript or the decision to submit the manuscript for publication. The authors are solely responsible for the contents. We acknowledge useful comments by Jeffrey Harris, Claudio Lucarelli, José Urquieta, Hugh Waters and various participants at seminars at the Mexican School of Public Health/National Institute of Public Health (INSP), the Mexican Central Bank, the European Conference on Health Economics (ECHE), and the American Society of Health Economists (ASHE). The comments of three anonymous referees also helped to improve the paper.

Open Access This article is distributed under the terms of the Creative Commons Attribution Noncommercial License which permits any noncommercial use, distribution, and reproduction in any medium, provided the original author(s) and source are credited.

\section{References}

1. Gakidou, E., Lozano, R., Gonzalez-Pier, E., et al.: Assessing the effect of the 2001-2006 Mexican health reform: an interim report card. Lancet 368, 1920-1935 (2006)

2. Knaul, F.M., Arreola-Ornelas, H., Mendez-Carniado, O., et al.: Evidence is good for your health system: policy reform to remedy catastrophic and impoverishing health spending in Mexico. Lancet 368, 1828-1841 (2006)

3. Parker, S.W., Wong, R.: Household income and health care expenditures in Mexico. Health Policy 40, 237-255 (1997)

4. Perez-Rico, R., Sesma-Vazquez, S., Puentes-Rosas, E.: Catastrophic health expenditures in Mexico: comparative study by social exclusion level. Salud Publica Mex 47(Suppl 1), S47-S53 (2005)

5. Sesma-Vazquez, S., Perez-Rico, R., Sosa-Manzano, C.L., et al.: Catastrophic health expenditures in Mexico: magnitude, distribution and determinants. Salud Publica Mex 47(Suppl 1), S37S46 (2005)

6. King, G., Gakidou, E., Imai, K., et al.: Public policy for the poor? A randomised assessment of the Mexican universal health insurance programme. Lancet 373, 1447-1454 (2009)

7. Frenk, J., Gonzalez-Pier, E., Gomez-Dantes, O., et al.: Comprehensive reform to improve health system performance in Mexico. Lancet 368, 1524-1534 (2006)

8. Knaul, F.M., Arreola-Ornelas, H., Mendez, O.: Financial protection in health: Mexico, 1992 to 2004. Salud Publica Mex 47, 430-439 (2005)

9. Torres, A.C., Knaul, F.M.: Determinantes del gasto de bolsillo en salud e implicaciones para el aseguramiento universal en México: 1992-2000. In: Knaul, F.M., Nigenda, G. (eds.) Caleidoscopio de la salud: De la investigación a las políticas y de las políticas a la acción, pp. 209-225. Fundación Mexicana para la Salud, México, D.F. (2003)

10. $\mathrm{Xu}, \mathrm{K}$. , Evans, D.B., Carrin, G., et al.: Protecting households from catastrophic health spending. Health Aff. (Millwood) 26, 972-983 (2007)
11. Van Damme, W., Van Leemput, L., Por, I., et al.: Out-of-pocket health expenditure and debt in poor households: evidence from Cambodia. Trop. Med. Int. Health 9, 273-280 (2004)

12. Von Neumann, J., Morgenstern, O.: Theory of games and economic behavior. Princeton University Press, Princeton (1944)

13. Friedman, M., Savage, L.J.: The utility analysis of choices involving risk. J. Polit. Econ. 56, 279-304 (1948)

14. Pauly, M.V.: The economics of moral hazard. Am. Econ. Rev. 58, 531-537 (1968)

15. Nyman, J.A.: The value of health insurance: the access motive. J. Health Econ. 18, 141-152 (1999)

16. McIntyre, D., Thiede, M., Dahlgren, G., et al.: What are the economic consequences for households of illness and of paying for health care in low- and middle-income country contexts? Soc. Sci. Med. 62, 858-865 (2006)

17. Xu, K., Evans, D.B., Kawabata, K., et al.: Household catastrophic health expenditure: a multicountry analysis. Lancet 362, 111-117 (2003)

18. Ranson, M.K.: Reduction of catastrophic health care expenditures by a community-based health insurance scheme in Gujarat, India: current experiences and challenges. Bull. World Health Organ. 80, 613-621 (2002)

19. Wang, H., Yip, W., Zhang, L., et al.: Community-based health insurance in poor rural China: the distribution of net benefits. Health Policy Plan 20, 366-374 (2005)

20. Chu, T.B., Liu, T.C., Chen, C.S., et al.: Household out-of-pocket medical expenditures and National Health Insurance in Taiwan: income and regional inequality. BMC Health Serv. Res. 5, 60 (2005)

21. Obermann, K., Jowett, M.R., Alcantara, M.O., et al.: Social health insurance in a developing country: the case of the Philippines. Soc. Sci. Med. 62, 3177-3185 (2006)

22. Wagstaff, A., van Doorslaer, E.: Catastrophe and impoverishment in paying for health care: with applications to Vietnam 19931998. Health Econ. 12, 921-934 (2003)

23. Limwattananon, S., Tangcharoensathien, V., Prakongsai, P.: Catastrophic and poverty impacts of health payments: results from national household surveys in Thailand. Bull. World Health Organ. 85, 600-606 (2007)

24. SSA: Sistema de Protección Social en Salud. Vols. 1-3. Secretaría de Salud (SSA), Gobierno de México., México, D.F., México (2006)

25. SSA: Catálogo Universal de Servicios de Salud 2008. Secretaría de Salud (SSA), Gobierno de México. http://www.seguropopular.salud.gob.mx/contenidos/menu_beneficios/beneficios_ doc_ref.html. Accessed 17 January 2008

26. SPSS: Sistema de Protección Social en Salud (SPSS): Informe de Resultados 2007. 1-104, Secretaría de Salud (SSA), Gobierno de México (2008)

27. SSA: Frequently Asked Questions about Seguro Popular. Secretaría de Salud (SSA), Gobierno de México. http://www.seguropopular.gob.mx/contenido.php?sccpmr_id=11. Accessed 17 February 2009

28. DOF: Decreto de Presupuesto de Egresos de la Federación para el Ejercicio Fiscal 2009: De la Asignación de Presupuesto de Egresos de la Federación (ed 28 November). 1-78, Diario Oficial de la Federación (DOF), Gobierno de México (2008)

29. CNPSS: Seguro Popular: Cobertura. Comisión Nacional de Protección Social en Salud (CNPSS), Secretaría de Salud, Gobierno de México. http://www.seguro-popular.salud.gob.mx/ contenidos/cobertura.html. Accessed 14 December 2007

30. Jowett, M., Contoyannis, P., Vinh, N.D.: The impact of public voluntary health insurance on private health expenditures in Vietnam. Soc. Sci. Med. 56, 333-342 (2003) 
31. Jowett, M., Deolalikar, A., Martinsson, P.: Health insurance and treatment seeking behaviour: evidence from a low-income country. Health Econ. 13, 845-857 (2004)

32. Wagstaff, A., Yu, S.: Do health sector reforms have their intended impacts? The World Bank's Health VIII project in Gansu province, China. J. Health Econ. 26, 505-535 (2007)

33. SSA: Seguro Popular: Encuesta de Evaluación de Impacto. Dirección General de Evaluación del Desempeño: Secretaría de Salud (SSA), Gobierno de México http://www.salud.gob.mx/ unidades/evaluacion/seguropopular/seguropopular.htm. Accessed 20 January 2008

34. INSP: Encuesta Nacional de Salud y Nutrición (ENSANUT). Instituto Nacional de Salud Pública (INSP). http://www.insp.mx/ ensanut/. Accessed 5 October 2007

35. King, G., Gakidou, E., Ravishankar, N., et al.: A "politically robust" experimental design for public policy evaluation, with application to the Mexican universal health insurance program. J. Policy Anal. Manage. 26, 479-506 (2007)

36. Heckman, J.J.: Dummy endogenous variables in a simultaneous equation system. Econometrica 46, 931-959 (1978)

37. Heckman, J.J., MaCurdy, T.E.: A simultaneous equations linear probability model. Can. J. Econ. 18, 28-37 (1985)

38. Greene, W.H.: Econometric analysis. Prentice Hall, Upper Saddle River (2003)

39. Maddala, G.S.: Econometric methods and applications. E. Elgar, Brookfield (1994)

40. Wooldridge, J.M.: Econometric analysis of cross section and panel data. MIT Press, Cambridge (2002)

41. Xu, K., Klavus, J., Kawabata, K.: Household health system contributions and capacity to pay: definitional, empirical and technical challenges. In: Murray, C., Evans, D., et al. (eds.) Health system performance assessment: debates, methods and empiricism, pp. 533-563. World Health Organization, Geneva (2003)

42. Murray, C., Knaul, F., Xu, K., et al.: Defining and measuring fairness of financial contribution, Global Programme on Evidence Working Paper No. 24. World Health Organization, Geneva (2000)

43. Verbeek, M.: A guide to modern econometrics, 3rd edn. Wiley, Chichester (2008)

44. Terza, J.V., Basu, A., Rathouz, P.J.: Two-stage residual inclusion estimation: addressing endogeneity in health econometric modeling. J. Health Econ. 27, 531-543 (2008)

45. Kawabata, K., Xu, K., Carrin, G.: Preventing impoverishment through protection against catastrophic health expenditure. Bull. World Health Organ. 80, 612 (2002)

46. Makinen, M., Waters, H., Rauch, M., et al.: Inequalities in health care use and expenditures: empirical data from eight developing countries and countries in transition. Bull. World Health Organ. 78, 55-65 (2000)

47. McKenzie, D.J.: Measuring inequality with asset indicators. J. Popul. Econ. 18, 229-260 (2004)
48. CONAPO: Índice de marginación a nivel localidad, 2005 Consejo Nacional de Población (CONAPO). http://www.conapo.gob.mx/ publicaciones/indice2005xloc.htm. Accessed 14 January 2008

49. Sepehri, A., Sarma, S., Simpson, W.: Does non-profit health insurance reduce financial burden? Evidence from the Vietnam Living Standards Survey Panel. Health Econ. 15, 603-616 (2006)

50. Trujillo, A.J., Portillo, J.E., Vernon, J.A.: The impact of subsidized health insurance for the poor: evaluating the Colombian experience using propensity score matching. Int. J. Health Care Finance Econ. 5, 211-239 (2005)

51. Sosa-Rubí, S.G., Galárraga, O., Harris, J.E.: Heterogeneous impact of the "Seguro Popular" program on the utilization of obstetrical services in Mexico, 2001-2006: a multinomial probit model with a discrete endogenous variable. J. Health Econ. 28, 20-34 (2009)

52. INEGI: Conteo de población y vivienda 2005 Instituto Nacional de Estadística, Geografía e Informática (INEGI). http://www. inegi.gob.mx/inegi/default.aspx?s=est\&c=10215. Accessed 12 January 2008

53. Angrist, J.D., Imbens, G.W., Rubin, D.B.: Identification of causal effects using instrumental variables. J. Am. Stat. Assoc. 91, 444455 (1996)

54. Angrist, J.D., Krueger, A.B.: Instrumental variables and the search for identification: from supply and demand to natural experiments. J. Econ. Perspect. 15, 69-85 (2001)

55. Heckman, J.J.: Instrumental variables: a study of implicit behavioral assumptions used in making program evaluations. J. Hum. Resour. 32, 441-462 (1997)

56. Waters, H.R.: Measuring the impact of health insurance with a correction for selection bias-a case study of Ecuador. Health Econ. 8, 473-483 (1999)

57. StataCorp: Stata Statistical Software: Release 9. StataCorp LP, College Station (2005)

58. Baum C.F., Schaffer M.E., Stillman S.: IVREG2: STATA Module for Extended Instrumental Variables/2SLS, GMM and AC/HAC, LIML and K-class Regression. http://ideas.repec.org/ c/boc/bocode/s425401.html. Accessed 7 October

59. Heckman, J.J.: Randomization as an Instrumental Variable: notes. Rev Econ Stat 78, 336-341 (1996)

60. Little R.J., Long Q., Lin X.: A comparison of methods for estimating the causal effect of a treatment in randomized clinical trials subject to noncompliance. Biometrics 65, 640-649 (2009)

61. King G., Gakidou E., Imai K., et al.: Public policy for the poor? A randomised assessment of the Mexican universal health insurance programme. Lancet 373, 1447-1454 (2009)

62. Pradhan, M., Prescott, N.: Social risk management options for medical care in Indonesia. Health Econ. 11, 431-446 (2002)

63. Hatt, L.E.: Measuring Risk Factors for Catastrophic Health Expenditures in Peru, and their Effects on Families over Time. Ph.D. Dissertation. Department of International Health 281, Johns Hopkins University, Baltimore (2006) 